\title{
ESPAÇOS LIVRES E MORFOLOGIA URBANA: \\ DISCUSSÕES SOBRE INFLUÊNCIAS NA \\ QUALIDADE CLIMÁTICA E SUSTENTABILIDADE \\ URBANA A PARTIR DE ESTUDOS EM CIDADES \\ NO ESTADO DE ALAGOAS - BRASIL ${ }^{1}$
}

\author{
OPEN SPACES AND URBAN MORPHOLOGY: DISCUSSIONS ON \\ CLIMATE IMPACTS AND URBAN SUSTAINABILITY: \\ A STUDY IN CITIES OF ALAGOAS, NORTHEAST BRASIL
}

\author{
Gianna Melo Barbirato* \\ Simone Carnaúba Torres** \\ Ricardo Victor Rodrigues Barbosa***
}

\section{RESUMO}

presente artigo traz reflexões sobre morfologia urbana, espaços livres e sua relação com a adequação climática e a sustentabilidade urbana, a partir da análise de mapas climáticos e cenários urbanos com o auxílio de simulações computacionais realizadas nas cidades de Maceió e Arapiraca, no Estado de Alagoas. Esses estudos revelam que os padrões de ocupação urbana determinados pelos atuais instrumentos de legislação urbanística não são capazes de potencializar o aproveitamento de condicionantes ambientais no meio urbano. Este artigo

Este artigo resulta do desenvolvimento de reflexões iniciadas pelo Grupo de Trabalho Legislação, integrante da Oficina Quapá-SEL organizada pela Coordenação Nacional da Rede Quapá-SEL e pelo Núcleo de Estudos de Morfologia dos Espaços (MEP), em maio de 2014, na Faculdade de Arquitetura e Urbanismo da Universidade Federal de Alagoas (UFAL).

* Arquiteta e urbanista pela Universidade Federal do Rio Grande do Norte (UFRN). Mestre e doutora pela Escola de Engenharia de São Carlos (EESC-USP). Professora associada da Faculdade de Arquitetura e Urbanismo da Universidade de Alagoas (UFAL). Campus A. C. Simões, avenida Lourival Melo Mota, s/n, Tabuleiro dos Martins, 5707-900, Maceió, AL, Brasil.

gmb@ctec.ufal.br

** Arquiteta, urbanista e mestre pela Universidade Federal de Alagoas (UFAL), Programa Dinâmicas do Espaço Habitado (DEHA). Doutoranda em Desenvolvimento Urbano na Universidade Federal de Pernambuco (UFPE). Professora do Curso de Arquitetura e Urbanismo da Universidade Federal de Alagoas. Campus Arapiraca, avenida Manoel Severino Barbosa, Bom Sucesso, 57309-005, Arapiraca, AL, Brasil.

simone.torres81@gmail.com

*** Arquiteto e urbanista pela Universidade Federal de Alagoas (UFAL). Mestre e doutor pela Escola de Engenharia de São Carlos (EESC-USP). Professor adjunto do Curso de Arquitetura e Urbanismo da Universidade Federal de Alagoas. Campus Arapiraca, avenida Manoel Severino Barbosa, Bom Sucesso, 57309-005, Arapiraca, AL, Brasil.

ricardovictor@bol.com.br 
destaca, também, a necessidade de revisão e refinamento destes para o alcance da adequação ambiental de espaços, enfatizando a possibilidade do estímulo ao adensamento construtivo fundamentado na capacidade de carga do sistema urbano.

Palavras-chave: Espaços livres. Morfologia urbana. Qualidade climática urbana. Sustentabilidade urbana.

\section{ABSTRACT}

This article shows reflections on urban morphology, open spaces and its relation to climate adaptation and urban sustainability. These studies, based on climatic maps analysis and computational simulations of urban scenarios in the cities of Maceió and Arapiraca, State of Alagoas, Northeast Brasil, reveal that the urban settlement patterns, determined by current instruments of urban legislation, are not able to maximize the use of environmental conditions in urban areas. It highlights the need to review and refinement of these to achieve the environmental suitability of spaces, emphasizing the possibility of stimulating density constructive patterns based on the carrying capacity of the urban system.

Keywords: Open spaces. Urban morphology. Urban climatic conditions. Urban sustainability.

\section{INTRODUÇÃO}

A vivência nas cidades, principalmente nas do cenário brasileiro e dos países subdesenvolvidos, tem sido caracterizada pela crescente perda da qualidade de vida, acompanhada de impactos ambientais decorrentes dos padrões de produção e consumo. Essa constatação é objeto de preocupação para profissionais de diversos campos do conhecimento, que, há décadas, se dedicam ao estudo de soluções para o alcance de novas formas de permanência, uso e produção do ambiente urbano, através de relações equilibradas entre o homem e o meio ambiente.

Um dos principais conceitos de sustentabilidade defendidos na atualidade baseia-se na necessidade de equilíbrio entre inputs e outputs no sistema urbano, resgatando referências da ecologia e do conceito de ecossistema. A sustentabilidade urbana, portanto, estaria mais próxima quanto menor o fluxo de entrada e saída de energia, materiais e resíduos de sua área.

Deve-se pensar, portanto, em soluções que promovam o resgate da qualidade de vida nas cidades e a redução dos impactos ambientais, tanto no nível da produção de resíduos, como no do consumo de recursos naturais (energia, água). Assim, o processo de urbanização deve ser fundamentado no redirecionamento do atual padrão de produção e consumo do espaço urbano, a partir da otimização da relação do homem com o meio natural.

que se percebe na contemporaneidade é que a expansão urbana nega os limites naturais impostos aos recursos finitos do planeta, pondo em conflito até o sistema econômico vigente, que promulga o desenvolvimento ilimitado do capital. (SILVA; ROMERO, 2011). Por isso, as cidades devem ser o foco principal para a definição de estratégias e políticas de desenvolvimento. $\bigcirc$ planejamento urbano, portanto, a partir de abordagens multidisciplinares, deve incorporar essas estratégias enfocando escopos da sustentabilidade, como a melhoria da qualidade de vida e o equilíbrio ambiental. 
Nessa perspectiva, insere-se o papel da bioclimatologia aplicada ao projeto arquitetônico e urbano. Fundamentada pelo princípio de adaptação dos elementos construídos ao meio ambiente, a partir de considerações climáticas, a bioclimatologia apresenta significativa contribuição para o alcance da sustentabilidade urbana, baseando-se no aproveitamento dos recursos passivos (naturais) de climatização dos espaços edificados.

A sustentabilidade urbana é definida por Acselrad (2009) como a capacidade de as políticas urbanas se adaptarem à oferta de serviços, à qualidade e à quantidade das demandas sociais, buscando o equilíbrio entre as demandas de serviços urbanos e os investimentos em estrutura. Nesse sentido, torna-se fundamental o uso racional dos recursos naturais, a boa forma do ambiente urbano, baseada na interação com o clima e os recursos naturais a partir de respostas às necessidades urbanas com o mínimo de transferência de dejetos e rejeitos para outros ecossistemas, atuais e futuros. Assim, o equilíbrio entre inputs e outputs no sistema urbano pode ser subsidiado pelo uso racional de energia a partir do aproveitamento dos recursos naturais de climatização - base conceitual da bioclimatologia arquitetônica e urbana.

Higueras (2006) reforçou o papel da bioclimatologia no planejamento dos espaços urbanos, difundindo o conceito de urbanismo bioclimático. A autora enfatiza a abordagem associada à capacidade de análise da carga dos sistemas naturais locais a uma matriz de interações entre os aspectos ambientais (insolação, ventos, vegetação) e as variáveis do ambiente urbano (estrutura de circulação, espaços livres e áreas verdes, lotes). A cidade bioclimática, portanto, deve incorporar instrumentos de planejamento urbano capazes de estimular o aproveitamento dos recursos naturais locais no nível do edifício e dos espaços externos urbanos, favorecendo a qualidade ambiental urbana e o bem-estar humano. A otimização da relação homem, espaço e meio natural, pode ser, assim, intermediada pelo urbanismo bioclimático, contribuindo para o alcance da sustentabilidade urbana.

A forma urbana desempenha importante papel para a aplicação de estratégias bioclimáticas nos espaços urbanos. Isso porque a densidade populacional indica o grau de compacidade de uma área urbana, e diferentes formas urbanas podem responder a um mesmo padrão de densidade com diferentes configurações de espaços abertos e, consequentemente, distintas condições microclimáticas.

Tratando-se de sustentabilidade urbana, a literatura especializada aponta que a malha urbana dispersa gera problemas ambientais em face ao espalhamento da estrutura urbana, eliminando coberturas vegetais nativas, aumentando demandas por consumo de energia, exigindo intenso uso de veículos para transporte de mercadorias e pessoas (aumentando a polvição do ar através da emissão de gases provenientes de combustíveis fósseis), afetando, também, a elevação da impermeabilização do solo natural decorrente da pavimentação excessiva (exercendo sérios danos ao ciclo hidrológico, causando enchentes, impactando o clima urbano). Por isso, o modelo da cidade compacta tem sido defendido.

Refletindo sobre o aspecto do adensamento construtivo urbano e sua relação com os estudos fundamentados na climatologia urbana, coloca-se em evidência o fenômeno 
da ilha de calor (decorrente do processo de elevação de temperatura no meio urbano). aumento do consumo de energia nos edifícios corresponde a uma consequência desse fenômeno devido à perda das condições de conforto térmico nos espaços urbanos e arquitetônicos, colocando em questionamento o estímulo ao alto adensamento construtivo urbano, apontado como solução mais adequada para o alcance da sustentabilidade urbana. Ora, se o alto adensamento construtivo pode provocar prejuízos em relação à formação do ambiente climaticamente modificado, como se deve tratar o adensamento urbano?

A partir da avaliação de cenários futuros, as pesquisas baseadas nos estudos de climatologia urbana apontam para a necessidade de revisão e incremento do processo normativo de planejamento urbano, principalmente no que concerne à definição dos parâmetros de ocupação de solo. As investigações sobre a influência da densidade construtiva na qualidade climática urbana, a partir da verificação dos graus de saturação do solo (cenários futuros), evidenciam a necessidade de tratamento dos espaços livres urbanos, pois estes apresentam alto potencial para favorecimento das condições de conforto térmico em espaços externos e internos da estrutura urbana.

É importante entender que as disciplinas urbanismo bioclimático e climatologia urbana já não consideram a solução da cidade compacta como contraditória. Ou seja, a bioclimatologia aplicada ao projeto urbano poderá subsidiar soluções que permitam o aumento do adensamento construtivo, considerando as implicações na estrutura urbana, para que o aproveitamento do potencial dos recursos naturais de climatização não se torne comprometido. Assim, o urbanismo bioclimático revela-se como disciplina com elevado potencial para a determinação de estratégias e diretrizes para a ocupação urbana de menor impacto ambiental, a partir do estabelecimento de padrões de adequação climática de assentamentos construtivos, podendo subsidiar soluções de morfologia urbana adequadas para o estabelecimento da cidade compacta.

Segundo Acselrad (2009), além da compactação urbana, é necessária a descentralização dos serviços e usos, pois os mesmos devem ser distribuídos das áreas centrais para as periferias, a fim de promover espaços urbanos menos segregados e mais igualitários. O autor destaca, dessa forma, a importância do controle demográfico paralelo às mudanças no processo de planejamento e gestão urbana.

Porém, o que se configura atualmente no cenário brasileiro ainda é o modelo estabelecido pelo espalhamento da malha urbana determinado pelos processos de exclusão social - representados tanto pela implantação de condomínios fechados, como pelos diversos conjuntos habitacionais de interesse social - e, principalmente, pelos assentamentos irregulares. Esse processo, portanto, revela-se incoerente em relação às novas discussões urbanas sobre sustentabilidade.

É urgente, portanto, a criação e revisão de políticas públicas de uso e ocupação do solo urbano para desestimular o crescente espraiamento da malha urbana das cidades brasileiras - o que corresponde a um dos principais desafios do planejamento urbano para implementação dos princípios da sustentabilidade urbana, pois envolve diversos aspectos da complexidade da gestão e do direito de propriedade urbana. 
É preciso compreender, ainda, que o estímulo ao aumento da densidade construtiva a partir da ocupação de determinados vazios urbanos pode eliminar algumas áreas de amenidades térmicas ou até mesmo estimular ocupações inadequadas, comprometendo o aproveitamento da ventilação natural na malha urbana. Por isso, torna-se importante a avaliação prévia desses impactos.

Sobre os impactos dos adensamentos construtivos urbanos, Freitas (2009) aponta a necessidade de revisão e análise do entendimento sobre o processo de urbanização e a consequente degradação ambiental. Em sua análise da cidade de Recife, conclui que a qualidade de vida e a sustentabilidade ambiental serão obtidas em cidades compactas quando preservada a alta densidade de vegetação e garantida a eficiência dos sistemas urbanos. Destaca, ainda, que "[...] os princípios norteadores do planejamento urbano e do projeto arquitetônico devem ser uma resposta aos dados climáticos locais, assim como ao resultado de experimentos de simulação de condições futuras [...]" (FREITAS, 2009, p. 71).

O adensamento construtivo urbano esbarra nos limites da capacidade de carga do espaço, tanto em relação ao aspecto da infraestrutura, como em relação ao aspecto ambiental. A bioclimatologia exerce papel fundamental no estabelecimento desses limites, e a legislação urbanística deve incorporar tais princípios.

Estudos da bioclimatologia devem subsidiar o processo de planejamento urbano, pois os parâmetros urbanísticos, definidos na legislação das cidades, agem diretamente sobre a densidade urbana. Esses parâmetros, embora determinem os limites de adensamento de uma determinada área, não podem ser utilizados universalmente, pois dependem de muitos condicionantes para que a adequação ambiental dos assentamentos construtivos seja alcançada.

Dessa forma, é reforçada a necessidade de ampliação dos estudos de climatologia urbana para a investigação dos graus de influência de diferentes parâmetros urbanísticos na determinação da qualidade ambiental urbana e, também, para a sistematização de procedimentos metodológicos que permitam a incorporação dos princípios bioclimáticos no processo de planejamento urbano.

No presente artigo, são apresentadas algumas reflexões sobre a importância da informação climática nesse processo, a partir de estudos empíricos nas cidades de Maceió e Arapiraca, fundamentados em avaliações de cenários e confecção de mapas climáticos. Destaca-se o papel dos espaços livres públicos na otimização da qualidade climática, evidenciando a necessidade de ajuste da morfologia urbana para potencializar o desempenho dos mesmos.

A cidade de Maceió, capital do Estado de Alagoas, vem passando por um processo de crescimento urbano caracterizado pela expansão desordenada da malha urbana e verticalização em alguns bairros, sobretudo na orla marítima. Já a cidade de Arapiraca, segunda maior do Estado, de médio porte, passa por processo de verticalização recente, com implantação de empreendimentos imobiliários - destacando-se a tipologia de condomínio vertical com conjuntos de edifícios com mais de dez pavimentos. 


\section{QUALIDADE AMBIENTAL E CARACTERÍSTICAS MORFOLÓGICAS URBANAS}

A qualidade ambiental dos espaços tem relação importante com a ocupação do solo. Uma mesma densidade urbana pode gerar diferentes tipologias espaciais na estrutura urbana, causando consequências microclimáticas diversas. Da mesma forma, diferentes formas urbanas podem responder a um mesmo padrão de densidade construtiva e populacional, com diferentes configurações de espaços abertos, condições microclimáticas e distribuições de uso, como exemplificadas no quadro 1.

O estudo apresentado no quadro 1 teve como objetivo identificar padrões de desempenho microclimático de tipologias espaciais urbanas caracterizadas por densidades construtivas e populacionais diferenciadas. Foi possível avaliar a importância da morfologia urbana e dos espaços livres na determinação de condições higrotérmicas dos ambientes estudados.

Foram realizadas simulações computacionais utilizando o freeware ENVI-Met versão 3.1, ferramenta que simula as relações entre estrutura urbana e ambiente, oferecendo possibilidades de aplicação e associações, permitindo a simulação do ambiente térmico urbano baseando-se em um conjunto de modelos físicos (BRUSE, 2007). As simulações permitiram identificar os pontos mais aquecidos e menos aquecidos nas tipologias espaciais estudadas, subsidiando a compreensão dos aspectos determinantes das condições climáticas locais. Os resultados referentes à análise do campo térmico das tipologias urbanas exemplificadas confirmaram a influência do padrão de exposição aos ventos predominantes e à radiação solar - e, também, as condições de revestimentos de solo no desempenho térmico dos espaços exteriores.

O padrão de exposição à radiação solar e a presença de revestimentos de solo de alta capacidade calorífica, como asfalto e concreto, demostraram ter significativa influência no desempenho térmico dos espaços externos. A ausência de arborização urbana também constitui fator determinante. Na tipologia 2, os valores máximos de temperatura do ar foram detectados na maior parte da extensão do recinto. Os valores mínimos foram registrados apenas no interior das quadras, em decorrência do sombreamento das edificações. Os maiores valores de temperatura do ar foram registrados nas vias pavimentadas com concreto com orientação nordeste-sudoeste (orientação desfavorável à penetração dos ventos predominantes). Como os lotes da tipologia 3 apresentam maior dimensão e menor taxa de ocupação (em média $30 \%$ a $50 \%$ ), os valores mínimos de temperatura foram identificados nos pontos de solo natural e maior velocidade dos fluxos de ar. Na tipologia 4, os valores máximos de temperatura foram obtidos nas vias pavimentadas de concreto, e os menores nos pontos de solo natural dos lotes residenciais.

O comportamento da temperatura do ar foi, portanto, influenciado pelas condições de revestimento do solo e morfologia do espaço edificado. Dessa forma, destaca-se o desempenho da tipologia 1, que apresenta densidade construtiva semelhante à identificada na tipologia 2 e densidade populacional superior. A presença de espaços livres 
Quadro 1 Tipologias Espaciais e Ambiente Térmico Resultante - Exemplo na Cidade de Arapiraca (AL), Contexto Semiárido do Nordeste Brasileiro.

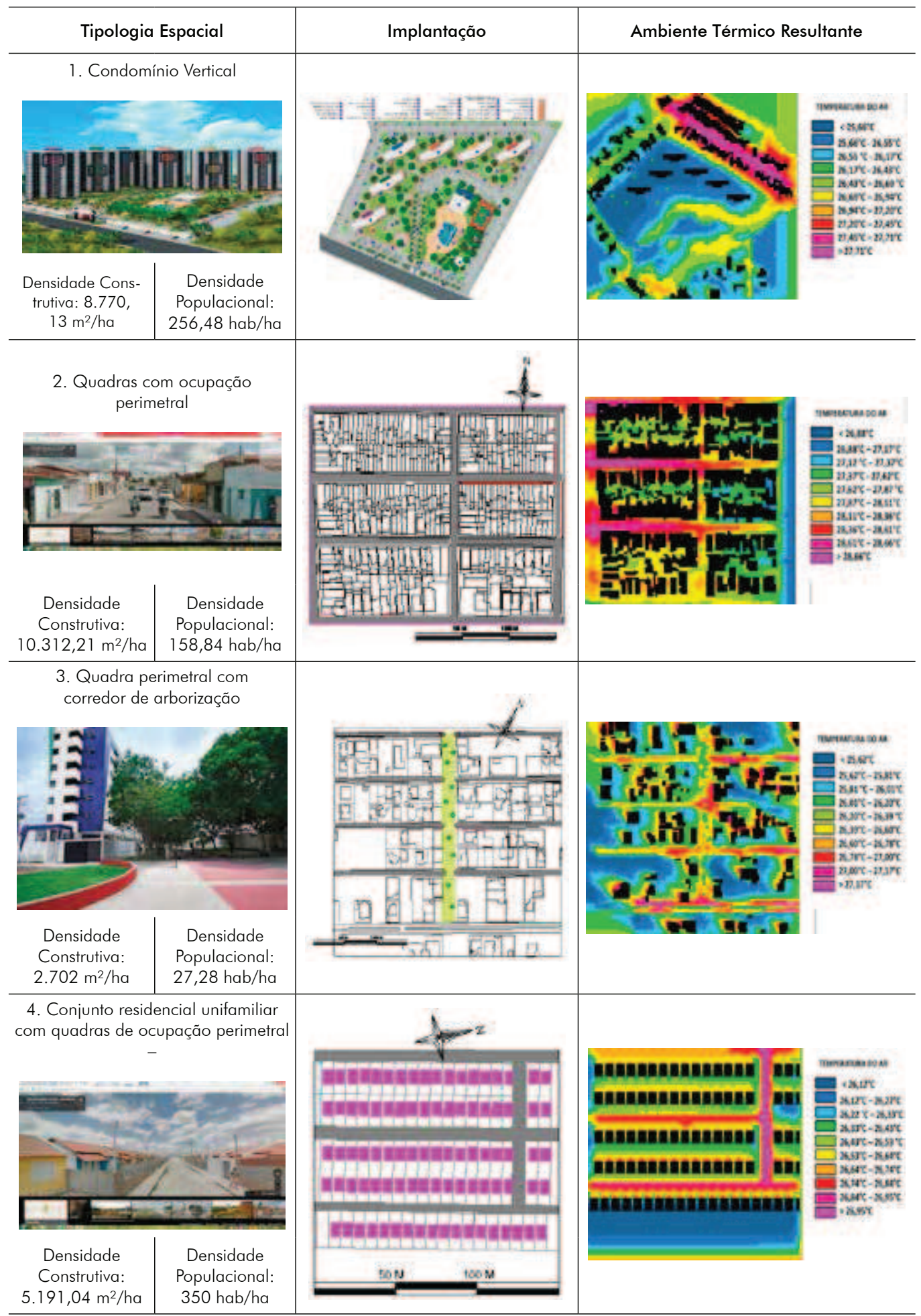

Fonte: Torres; Freitas; Barbirato (2014) 
no interior do condomínio, caracterizada pela existência de vegetação e solo natural, em área à barlavento (incidência direta de ventilação predominante), contribuiu para a determinação de microclima de amenização das condições climáticas locais. A tipologia de ocupação vertical da quadra, determinada pela conservação de espaços livres, apesar da densidade construtiva elevada, apresentou desempenho semeIhante ao encontrado na tipologia 3 (menor densidade construtiva e populacional).

A morfologia do conjunto edificado constitui fator determinante dos campos térmicos urbanos. A densidade construtiva não pode ser apontada como principal vilã nos fenômenos de aquecimento urbano. $O$ desenho urbano e a configuração dos espaços livres podem ser estudados para minimizar os impactos na qualidade climática urbana. Para que o desempenho climático seja otimizado, é necessário estudar os diferentes tipos de morfologia e ocupação do solo.

Nesse contexto, o padrão tradicional de legislação para controle e ordenamento da ocupação do solo, que utiliza como unidade mínima o lote urbano, pode constituir uma barreira para implantação de soluções mais eficazes para o aproveitamento dos condicionantes ambientais (ventilação natural, iluminação natural e resfriamento evaporativo através da vegetação) no interior da estrutura urbana. Dessa forma, a utilização da quadra como elemento mínimo para o controle de ocupação, através da legislação urbana, pode subsidiar novas respostas para o favorecimento do desempenho do termo energético do ambiente urbano, no nível microclimático, devido à possibilidade de estímulo à conservação e configuração de espaços livres com potencial para incorporação das estratégias bioclimáticas (solo natural e eliminação das barreiras aos ventos predominantes locais). Os estudos que serão apresentados a seguir reforçam essa ideia.

Sabe-se que, em cidades de clima tropical, onde a temperatura é alta durante todo o ano, a preocupação com a implantação e manutenção de áreas verdes deve estar associada à sua distribuição na malha urbana para que haja uma relação proporcional e compatível entre as áreas verdes e a massa edificada. A vegetação proporciona o sombreamento das áreas urbanas, criando um microclima próprio que influencia de forma positiva na amenização dos efeitos térmicos no entorno próximo. Além disso, espaços com solo permeável contribuem para absorção de maior quantidade de radiação solar, irradiando menor quantidade de calor para o meio externo.

\section{PARÂMETROS URBANÍSTICOS E SUAS CONSEQUÊNCIAS NOS ESPAÇOS URBANOS}

\subsection{ANÁLISE DE CENÁRIOS URBANOS E PROGNÓSTICOS FUTUROS}

A inserção da questão climática na prática do planejamento urbano, quer seja na previsão das condições microclimáticas que devem ser preservadas quando o crescimento urbano é necessário, ou na previsão das consequências de alternativas de pro- 
postas, torna-se cada vez mais importante. Desse modo, a possibilidade de trabalhar com simulações computacionais que mostrem diversas alternativas de organização dos espaços urbanos, fundamentadas em critérios ambientais, como o conforto térmico dos ambientes urbanos, pode ser útil na demonstração das dinâmicas do microclima urbano em busca do conforto térmico.

As figuras la e $1 b$ mostram o esquema de um arranjo urbano em sua forma atual e um cenário hipotético futuro para a mesma área, localizada na cidade de Maceió $(\mathrm{AL})$, considerando a máxima verticalização permitida pela legislação local, com taxa de ocupação de $20 \%$. A área é considerada de adensamento controlado, ocupação predominantemente residencial, com verticalização de até vinte pavimentos e possibilidade de instalação de atividades comerciais, de serviços e industriais.

Simulações computacionais com o programa ENVI-Met (BRUSE, 2007) mostraram, para o caso estudado, que o aumento na altura das edificações atenua a temperatura do ar no nível microclimático pelo efeito de sombreamento originado pelas edificações. Por outro lado, o cenário futuro mostrou baixa fluidez dos ventos pela influência da altura das edificações como elementos de obstáculo.

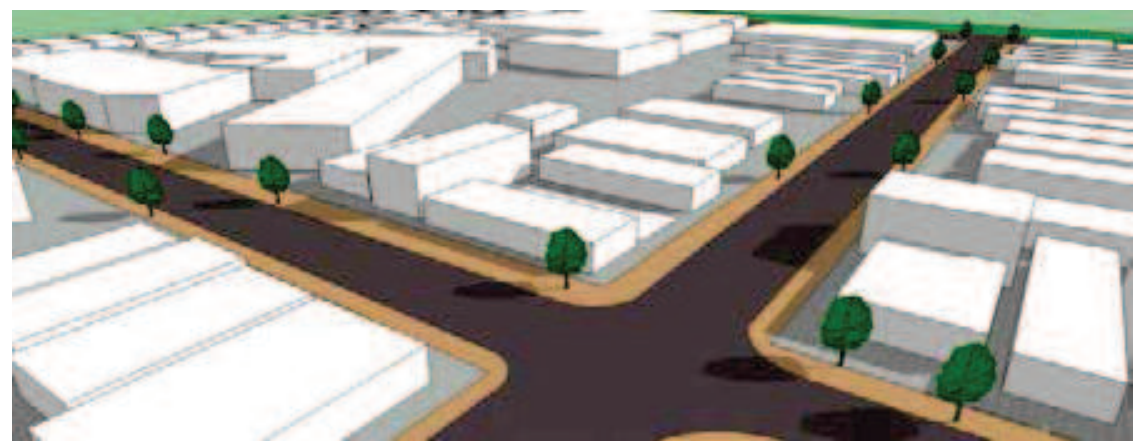

Figura la Modelo tridimensional de uma porção urbana da cidade de Maceió, AL, Brasil. Fonte: Cruz; Barbirato (2014)

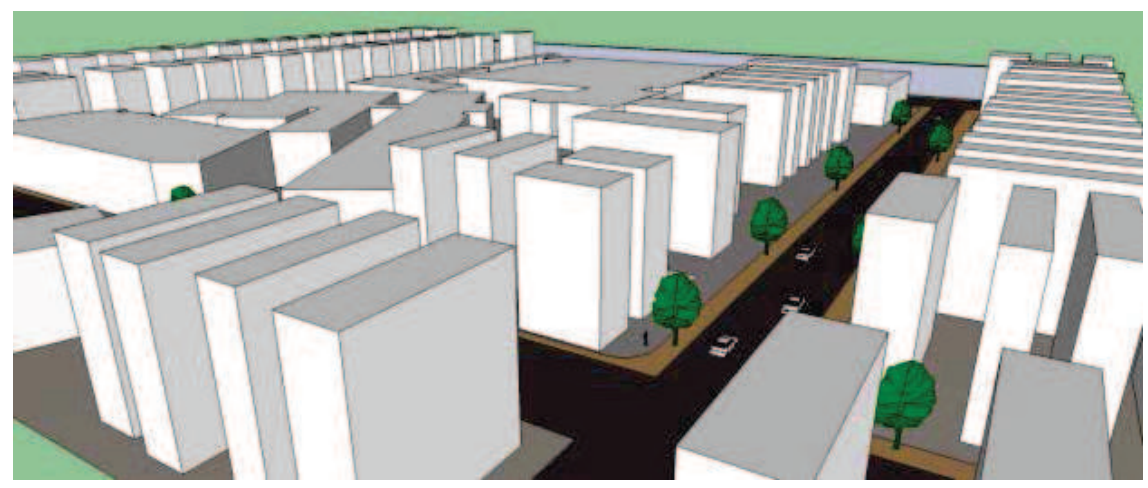

Figura $1 \mathrm{~b}$ Prognóstico futuro com verticalização máxima permitida pela legislação local. Fonte: Cruz; Barbirato (2014)

Da mesma forma, o quadro 2 apresenta o resultado das simulações computacionais de diferentes alternativas de ocupações, considerando diferentes parâmetros urbanos 
(taxa de ocupação e limite vertical de edificações) para a mesma área urbana anteriormente exemplificada, de modo a verificar possíveis modificações microclimáticas. Os mapas apresentados identificam os parâmetros urbanísticos permitidos pela legislação urbana para a área estudada.

Quadro 2 Comportamento Térmico de Diferentes Configurações Urbanas em Cidade com Clima Quente e Úmido do Nordeste Brasileiro - Maceió (AL)

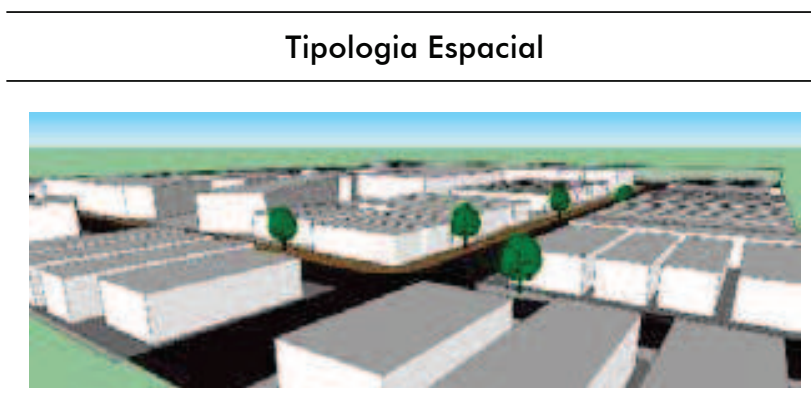

A) $60 \%$ de taxa de ocupação e limite vertical de dois pavimentos Ambiente térmico resultante (15 h)

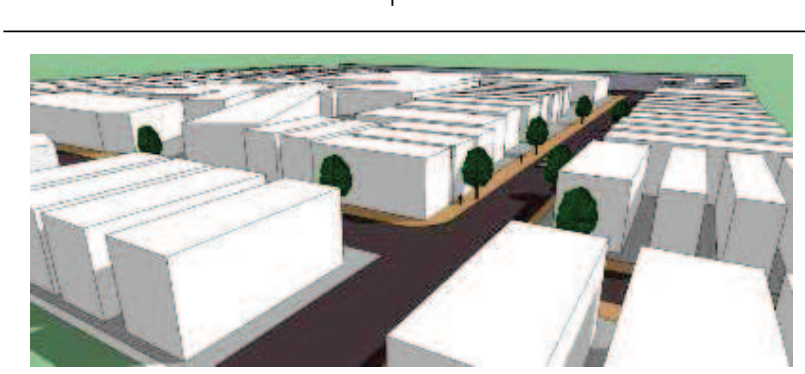

B) $50 \%$ de taxa de ocupação e limite vertical de dez pavimentos

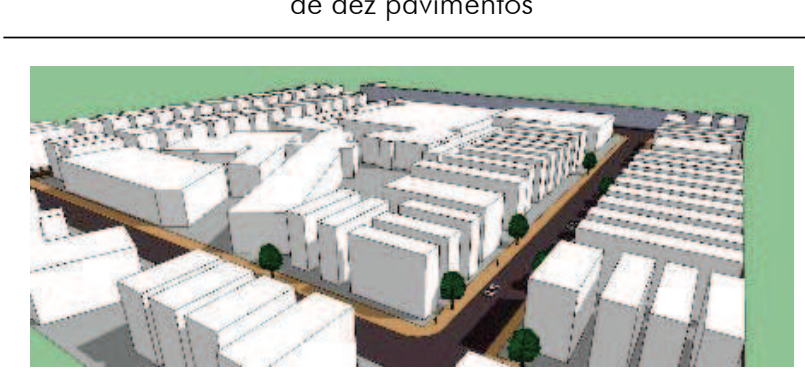

C) $35 \%$ de taxa de ocupação e limite vertical de quinze pavimentos
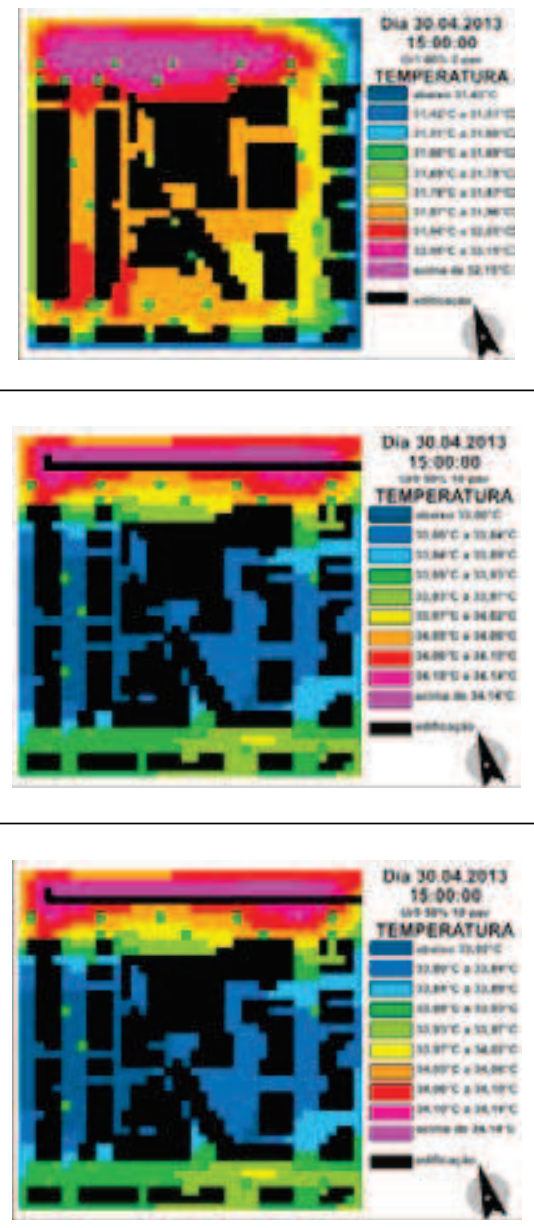

Fonte: Cruz; Barbirato (2014)

Os resultados apontaram menores valores de temperatura nos cenários A $160 \%$ de taxa de ocupação e altura de dois pavimentos das edificações) e C (35\% de taxa de ocupação e altura de quinze pavimentos das edificações). No cenário de maior taxa de ocupação (60\%), o limite de verticalização é menor. No cenário C, nota-se que, embora haja maior verticalização, a taxa de ocupação baixa garante maior porosidade e conformação menos compacta da área edificada. $O$ cenário $B$, correspondente a 
50\% de taxa de ocupação e limite vertical de dez pavimentos, foi o que apresentou maiores valores térmicos, provavelmente, por apresentar características singulares em comparação aos outros cenários, como taxa de ocupação e limite vertical, que, juntos, resultaram em fatores mais transformadores do microclima que os demais.

\subsection{MAPA CLIMÁTICO COMO SUBSÍDIO AO PLANEJAMENTO URBANO}

Uma das alternativas apontadas pela literatura especializada em climatologia urbana - para levantamento de informações quanto ao processo de adequação climática da estrutura edificada urbana - é a produção de mapas climáticos. (KATZSCHNER, 1997). Essa metodologia baseia-se na descrição qualitativa das características espaciais dos recintos urbanos para o desenvolvimento de um sistema de classificação. Primeiramente, é realizada uma análise geográfica a partir da confecção de mapas de uso do solo e caracterização da estrutura urbana, como estratificação das edificações (altura, profundidade e largura). A sobreposição desses mapas a partir da integração das informações sobre as condições das superfícies urbanas é correlacionada com a temperatura e umidade relativa do ar próximo ao solo (medições microclimáticas), onde os resultados analisados permitem desenvolver um sistema de classificação das condições termodinâmicas. A validação e correção dos mapas são finalizadas com a confecção de um mapa climático padrão, que inclui os fatores do sistema de classificação do clima urbano.

Utilizando como base o mapa climático desenvolvido em Melo (2009) para a cidade de Maceió (AL), é possível verificar alguns conflitos entre as diretrizes de planejamento urbano local e o mapa gerado. Através da sobreposição das informações do sistema de classificação do mapa clima climático (diagnóstico das áreas urbanas a serem protegidas, áreas a serem preservadas e áreas a serem melhoradas) com as informações do macrozoneamento urbano local, previstas no Plano Diretor de Maceió (MACEIÓ, 2005), e do Código de Urbanismo e Edificações (MACEIÓ, 2007), que estabelece os parâmetros de ocupação urbana, verifica-se a necessidade de revisão das diretrizes de planejamento urbano local para que a qualidade climática urbana não seja comprometida.

Para explicitar esse fato, pode-se comparar as diretrizes especificadas para a zona referente a "áreas a serem protegidas" delimitadas no Mapa Climático de Maceió (MELO, 2009) com a área correspondente no macrozoneamento urbano previsto no Plano Diretor, a Zona de Expansão Urbana (figura 2). Segundo o estudo, as áreas a serem protegidas em Maceió compreendem zonas com boas condições de conforto térmico e microclima urbano satisfatório (figura $2 a$, mancha em azul). São áreas na cidade, localizadas em cotas topográficas mais elevadas, com traçado urbano favorável à incidência dos ventos predominantes. Portanto, o estudo destaca que novas intervenções arquitetônicas e urbanísticas devem ser avaliadas a fim de não comprometer a qualidade térmica do espaço urbano. 
Segundo as diretrizes do Plano Diretor de Maceió (MACEIÓ, 2007) para a Macrozona de Expansão Urbana da cidade (figura 2b, mancha em vermelho), deve ser estimulada a ocupação dos vazios urbanos - apontada para o alcance da sustentabilidade urbana - como estratégia para evitar o espalhamento e a dispersão da malha urbana. Porém, avaliando os parâmetros urbanísticos especificados em legislação complementar, verifica-se o estímulo a padrões climaticamente inadequados de ocupação do solo, ou seja, padrões que não permitem o alcance das diretrizes apontadas no mapa climático local.
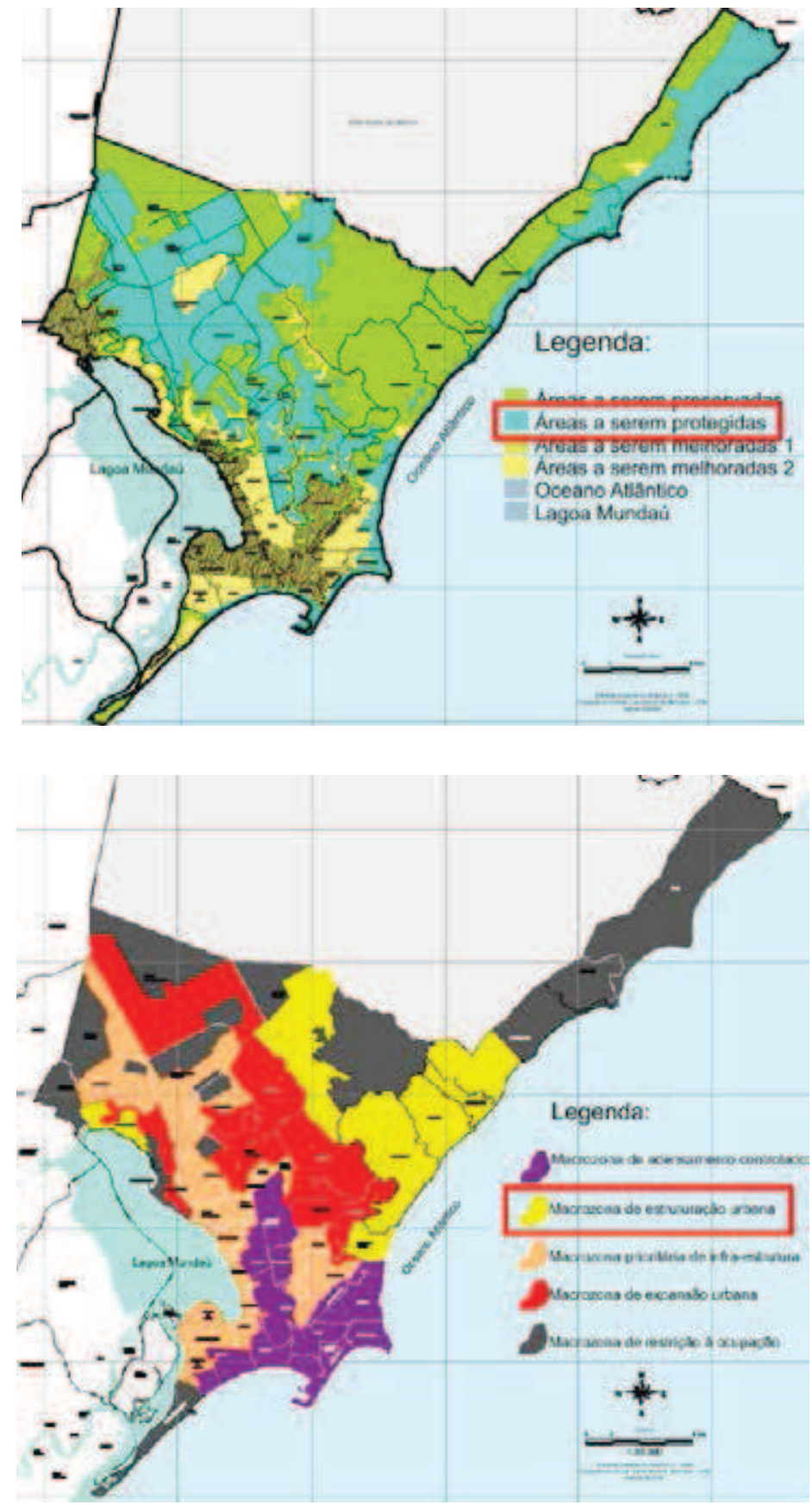

Figura 2a Mapa climático de Maceió segundo Duarte (2009). Destaque à zona denominada "áreas a serem protegidas" (mancha azul).

Fonte: Elaborada pelo Grupo de Trabalho Legislação da Oficina Quapá-SEL UFAL (2014) a partir de Duarte (2009).
Figura 2b Macrozoneamento urbano de Maceió segundo o Plano Diretor local. Destaque para a área correspondente à Zona de Expansão Urbana (mancha vermelha), área correspondente à citada na figura 2a.

Fonte: Elaborada pelo Grupo de Trabalho Legislação da Oficina Quapá-SEL UFAL (2014) a partir de Maceió (2005). 
A partir dos parâmetros urbanísticos estabelecidos para o uso residencial 1 - UR1 (quando na gleba ou no lote for implantada uma unidade residencial unifamiliar) e uso residencial 5 - UR5 (quando na gleba ou lote for implantada uma edificação multifamiliar com três ou mais pavimentos), foram analisados os possíveis efeitos quanto às modificações de uma futura saturação da ocupação do solo urbano (quadro 3).

Quadro 3 Exemplo de Parâmetros Urbanísticos em Zona Residencial para Usos Distintos em Maceió (AL)

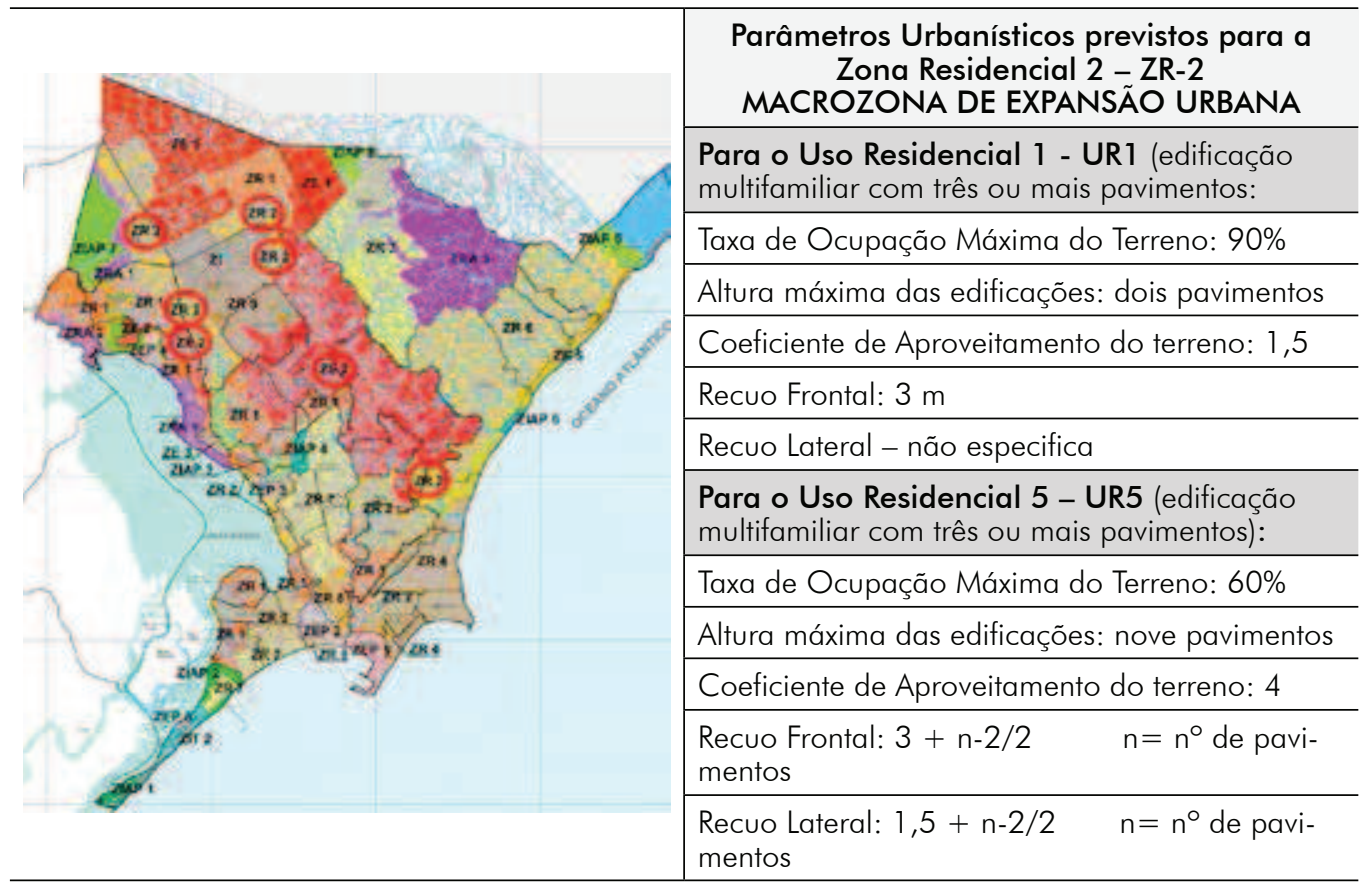

Fonte: Elaborado pelo Grupo de Trabalho Legislação da Oficina Quapá- SEL UFAL (2014) a partir de Maceió (2005).

Aplicando-se o uso dos parâmetros máximos estabelecidos para o UR-1 e UR-5 na Macrozona de Expansão Urbana, verifica-se que os padrões de ocupação do solo urbano serão desfavoráveis ao aproveitamento dos condicionantes naturais, prejudicando o desempenho termoenergético dessas estruturas urbanas (figura 3). Entre os efeitos indesejados em relação à qualidade climática local, os principais são:

\section{Para a UR-1:}

- canalização dos ventos nas vias, devido à proximidade entre as edificações, decorrente da ausência do estabelecimento de recuos laterais;

- impossibilidade do aproveitamento dos ventos no nível dos edifícios, pois as massas de ar serão canalizadas apenas nas vias; a estrutura edificada não será capaz de favorecer a penetração dos ventos entre as edificações; o aproveitamento da 
estratégia bioclimática ventilação natural nas edificações, como alternativa para resfriamento e minimização do consumo de energia, não será viabilizado;

- tendência à impermeabilização total dos lotes, gerando acúmulo de calor devido ao elevado volume construtivo, com alta capacidade calorífica e baixa capacidade de resfriamento devido à ausência de elementos para amenização térmica, como solo úmido natural e arborização.

\section{Para a UR-5:}

- elevada perda de velocidade dos ventos predominantes e formação de grandes áreas de estagnação do ar devido à formação de estrutura verticalizada pouco porosa (baixa rugosidade);

- impossibilidade de aproveitamento dos ventos predominantes locais no nível do edifício e de iluminação natural devido à redução da exposição da radiação solar entre blocos construídos em proximidade;

- tendência à formação do fenômeno ilha de calor devido à alta capacidade calorífica e baixa capacidade de dissipação de energia térmica acumulada.

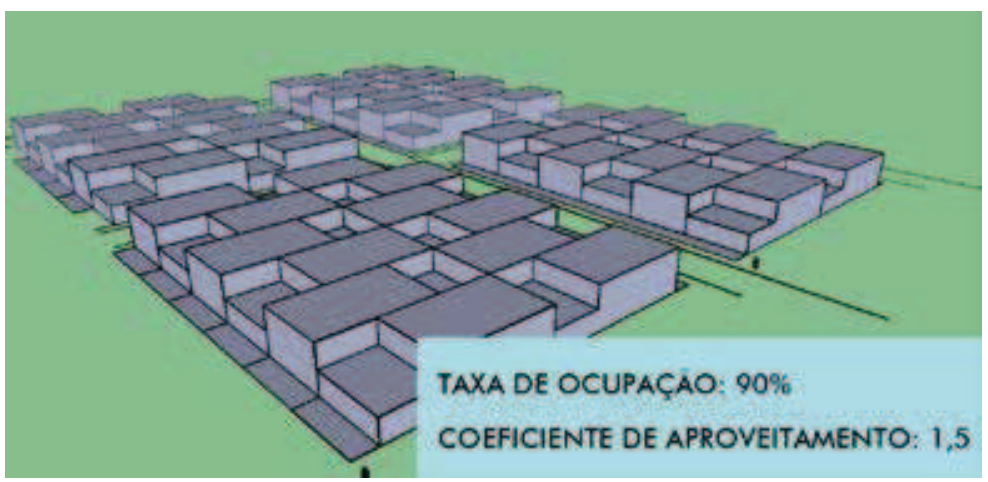

Figura 3a Saturação do solo urbano segundo parâmetros de ocupação máxima previstos para o UR-1 na ZR-2 (Macrozona de Expansão Urbana).

Fonte: Grupo de Trabalho Legislação da Oficina Quapá-SEL UFAL (2014).

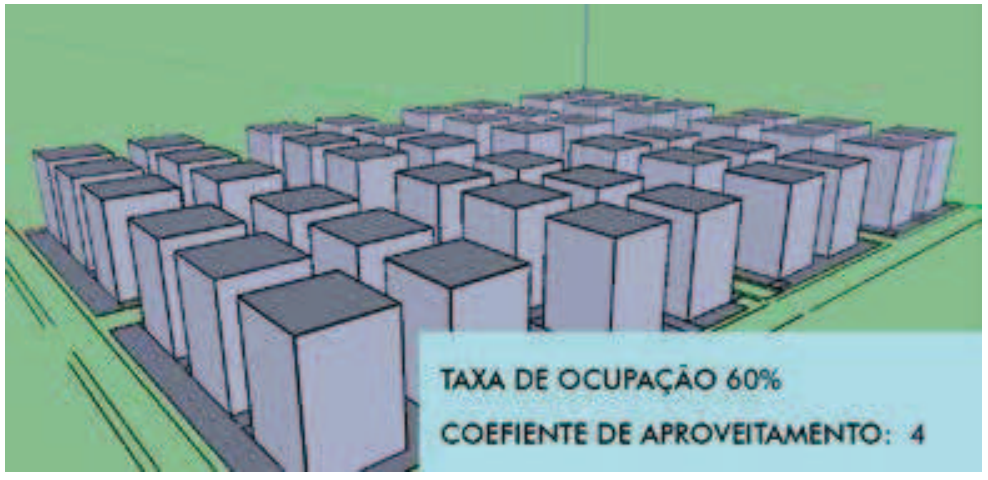

Figura 3b Saturação do solo urbano segundo parâmetros de ocupação máxima previstos para o UR-5 na ZR-2 (Macrozona de Expansão Urbana).

Fonte: Grupo de Trabalho Legislação da Oficina Quapá-SEL UFAL (2014). 
Conclui-se, assim, que instrumentos como mapas climáticos devem ser considerados no processo de revisão da legislação urbanística local. Os parâmetros urbanísticos estabelecidos para a ZR-2 da Macrozona de Expansão Urbana precisam ser estudados e redefinidos para permitir maior porosidade e rugosidade da estrutura edificada futura, para potencializar o aproveitamento das estratégias bioclimáticas tanto no nível do edifício, como no nível dos ambientes externos urbanos. Uma das alternativas é estimular a baixa ocupação do solo e aumentar o coeficiente de aproveitamento. Porém, outras estratégias, mais eficientes, que permitam o maior controle sobre o uso e ocupação do solo, principalmente quanto à manutenção da taxa de permeabilidade, podem ser estudadas.

Para o caso específico mostrado, deve-se permitir o incremento da rugosidade da estrutura edificada e otimizar o aproveitamento da ventilação natural. Sugere-se que a quadra, ao invés do lote, seja o elemento mínimo sobre o processo de fiscalização e controle da ocupação urbana (figura 4). Dessa forma, será possível viabilizar a manutenção das taxas de solo natural e a incorporação de áreas de vegetação urbana a partir da distribuição eficaz de espaços livres com alto potencial de amenização térmica local. Na figura 4, apresenta-se um exemplo de ocupação de quadra aberta com mesma densidade construtiva máxima prevista para o UR-5 na ZR-E (Macrozona de Expansão Urbana), porém, com o aumento da rugosidade e porosidade urbana, necessário para a manutenção das condições de conforto térmico local. Além das vantagens para o micro e mesoclima, essa morfologia modificada será capaz de estimular o uso dos espaços livres, como espaços livres públicos, favorecendo o uso destes pelas comunidades urbanas locais.

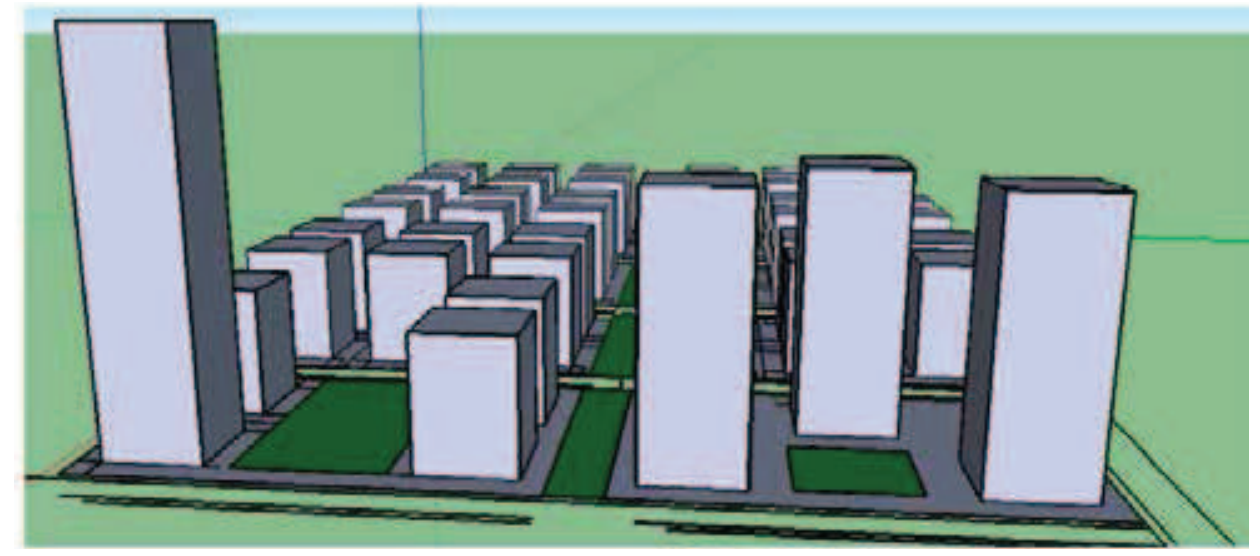

Figura 4 Exemplo da modificação da morfologia urbana, utilizando-se a mesma densidade construtiva prevista para o UR-5 na ZR-2 (Macrozona de Expansão Urbana).

Fonte: Grupo de Trabalho Legislação da Oficina Quapá-SEL UFAL (2014).

É importante ressaltar que, além da configuração da estrutura edificada, a morfologia dos espaços destinados a vias públicas, equipamentos urbanos e áreas livres para lazer pode ser também estudada para potencializar o efeito de amenização térmica dos ambientes urbanos. 
Na legislação federal, a Lei n 6.766/1979 (BRASIL, 1979), sobre o parcelamento do solo urbano, estabelece que para novos loteamentos é exigida a destinação de $20 \%$ para vias públicas, $10 \%$ para áreas livres de lazer e 5\% para equipamentos comunitários. A distribuição dessas áreas pode favorecer as condições microclimáticas locais, desde que o desenho urbano seja estudado para permitir a integração entre os espaços livres. Porém, atualmente, não há muita preocupação com a definição dessas áreas, tornando menor o estímulo ao atendimento dos requisitos ambientais e até mesmo sociais.

No quadro 4, são apresentados alguns exemplos de loteamentos existentes na área de expansão urbana de Maceió. Destacam-se, em amarelo, os espaços destinados aos equipamentos urbanos, e, em verde, os espaços de lazer.

Quadro 4 Exemplos de Loteamentos Urbanos na Área de Expansão Urbana de Maceió: Análise do Padrão de Desenho Urbano

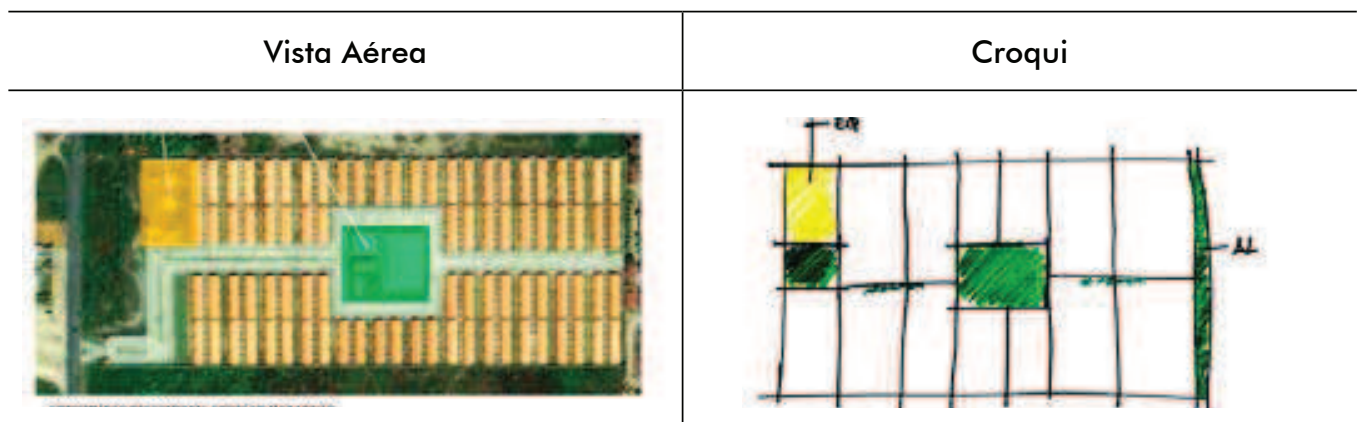

1. Condomínio Residencial Ernesto Maranhão

Padrão de espaços livres isolados/fragmentados
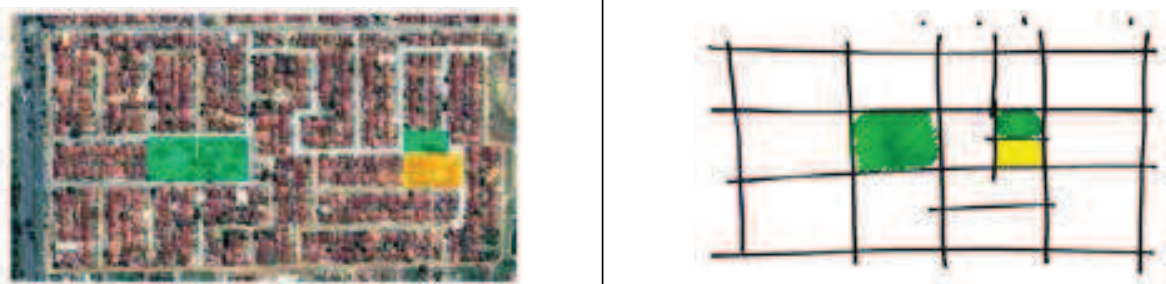

2. Conjunto Cidade Universitária

Padrão de espaços livres isolados/fragmentados
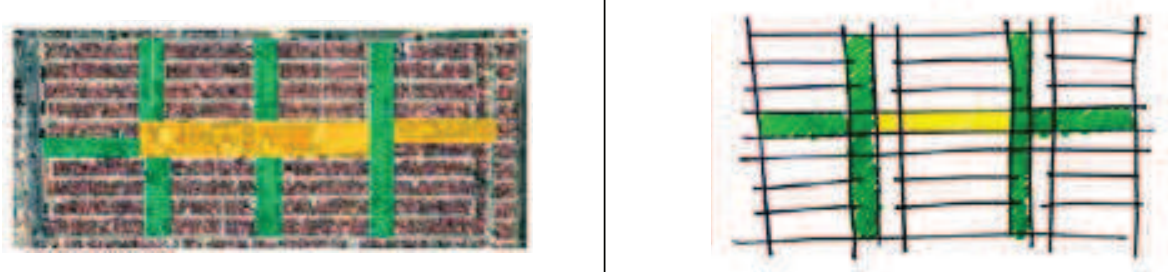

3. Conjunto Eustáquio Gomes

Padrão de espaços livres integrados

Fonte: Grupo de Trabalho Legislação da Oficina Quapá-SEL UFAL (2014). 
Através desses exemplos, pode-se concluir que, no caso dos loteamentos caracterizados pelo padrão de desenho de espaços livres isolados/fragmentados, o potencial de amenização térmica é reduzido (figura 5 a). Já no caso de espaços livres integrados, o feito da amenização térmica de áreas arborizadas e livres de barreiras para ventilação natural é mais eficaz, aumentando o potencial de adequação climática da estrutura urbana (figura $5 b$ ).

Nesse sentido, ressalta-se a importância da compreensão dos parâmetros climatológicos para a análise e projeto da estrutura urbana edificada. Os mesmos podem complementar a visão do planejador urbano, de maneira que os parâmetros urbanísticos tradicionais (taxa de ocupação, recuos, coeficiente de aproveitamento, taxa de ocupação), correspondam aos atributos bioclimatizantes da forma urbana, como a rugosidade, a porosidade e o fator de visão de céu, a fim de estimular respostas positivas para o alcance da qualidade de vida no meio urbano, principalmente através da contribuição ambiental e social dos espaços livres públicos.

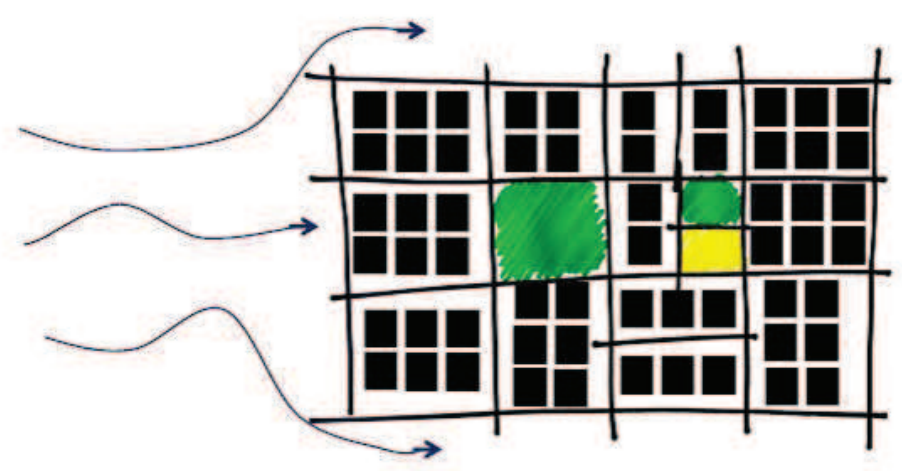

Figura 5a Desenho urbano desfavorável à dissipação de energia térmica - pouca distribuição do efeito microclimático do espaço livre.

Fonte: Grupo de Trabalho Legislação da Oficina Quapá-SEL UFAL (2014).

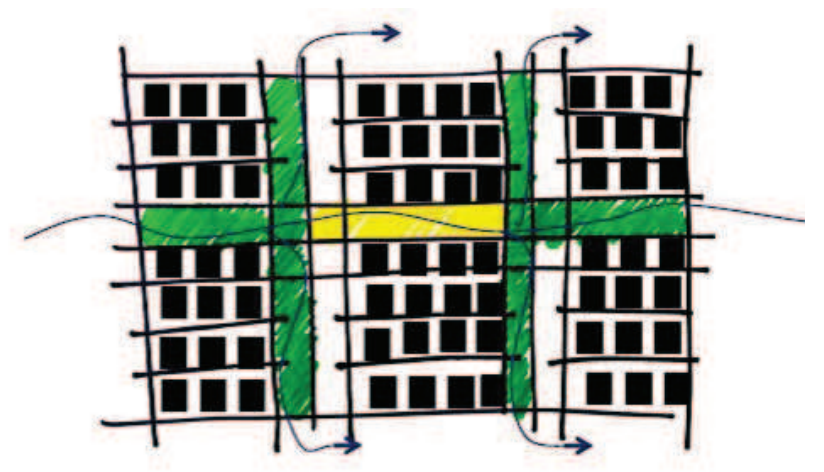

Figura 5b Desenho urbano favorável à dissipação da energia térmica - boa distribuição das massas de ar e do efeito microclimático do espaço livre.

Fonte: Grupo de Trabalho Legislação da Oficina Quapá-SEL UFAL (2014). 


\section{CONSIDERAÇÕES FINAIS}

As reflexões e estudos fundamentados na climatologia urbana abordados neste artigo evidenciam o potencial da inserção da questão climática na prática do planejamento urbano, na previsão das condições microclimáticas ou na simulação de alternativas de propostas de planejamento e seus possíveis efeitos.

É importante destacar que os resultados e análises apresentados correspondem a estudos empíricos determinados por contextos climáticos específicos (quente e úmido e semiárido do Nordeste brasileiro). Assim, as recomendações podem ser aplicáveis em contextos mais abrangentes desde que sejam consideradas as particularidades climáticas adotadas na generalização do presente estudo.

De acordo com as contribuições teóricas desenvolvidas através dos estudos de climatologia urbana, as principais diretrizes de planejamento para construção da cidade bioclimática permeada pelos princípios da sustentabilidade urbana são as seguintes:

- promover linhas de ação baseadas nas considerações das particularidades dos sítios urbanos (clima, topografia, cultura); cada sítio deve apresentar medidas específicas dentro de sua própria integração territorial com outros assentamentos urbanos;

- promover o uso misto e diversidade de atividades concentradas em áreas urbanas centrais para reduzir as viagens e o consumo de energia para o transporte, incentivando rotas pedestres;

- integrar, ampliar e, convenientemente, projetar a rede de espaços urbanos abertos como um sistema capaz de corrigir e moderar extremas condições ambientais adversas e servir como espaço de relacionamento e uso social;

- efetivar o planejamento através do estímulo de densidades (construtivas) moderadas ou altas em comparação com a baixa densidade de casas dispersas, onde o custo da energia, da infraestrutura e do impacto sobre o meio ambiente são muito elevados;

- incentivar a utilização de técnicas arquitetônicas para condicionamento passivo, oferecendo soluções possíveis para as necessidades da economia de energia; considerar a cobertura como a quinta fachada, com grande potencial para o controle do conforto ambiental.

É importante que haja maior articulação entre as legislações urbanísticas responsáveis pelo ordenamento das cidades e as características climáticas de ambientes externos por meio da elaboração de diretrizes que incorporem o enfoque climático nos instrumentos de planejamento urbano (planos diretores), com vistas a um planejamento urbano-ambiental climaticamente adequado. Nesse sentido, é importante que as informações produzidas no âmbito acadêmico sejam integradas às ações de gestão pública, contribuindo na resolução de problemas ambientais urbanos com a incorporação de parâmetros urbanísticos que reflitam a existência de espaços construídos mais adequados às condições climáticas locais. 
Este estudo destaca a necessidade de revisão e refinamento destes para o alcance da adequação ambiental de espaços construídos como forma de garantir boas condições de conforto térmico nos ambientes internos das edificações urbanas, enfatizando a possibilidade do estímulo a adensamentos construtivos fundamentados na capacidade de carga do sistema urbano.

Por fim, registra-se aqui a necessidade de pesquisas que mostrem a importância de prognósticos climáticos urbanos, que auxiliem nas discussões sobre prescrições urbanísticas e planejamento de cidades.

\section{REFERÊNCIAS BIBLIOGRÁFICAS}

ACSELRAD, Henri (Org.). A duração das cidades: sustentabilidade e risco nas políticas urbanas. Rio de Janeiro: Lamparina, 2009. 256 p.

BRASIL. Lei n 6.766, de 19 de dezembro de 1979. Dispõe sobre o Parcelamento do Solo Urbano e dá outras providências. Brasília: Diário Oficial da União, 1979, p. 19457.

BRUSE, M. ENVI-Met ${ }^{\circledR}$ model homepage. 2007. Disponível em: <www.envi-met.com>. Acesso em: 30 ago. 2013.

CRUZ, Maiara da Silva; BARBIRATO, Gianna Melo. Aplicação de ferramentas da climatologia urbana como subsídio às diretrizes do Plano Diretor: exemplo de aplicação em cidade do Nordeste do Brasil. In: CONGRESSO LUSO BRASILEIRO PARA O PLANEJAMENTO URBANO, REGIONAL, INTEGRADO E SUSTENTÁVEL, 6, 2014, Lisboa. Anais PLURIS 2014. Lisboa: Fundação Calouste Gulbenkian, 2014, p. 2746-2757.

FREITAS, Ruskin. Entre mitos e limites: as possibilidades de adensamento construtivo face à qualidade de vida no ambiente urbano. UFPE, 2009. 270 p.

HIGUERAS, Ester. Urbanismo bioclimático. Barcelona: Gustavo Gili, 2006. 242 p.

KATZSCHNER, Lutz. Urban climate studies as tools for urban planning and architecture. In: ENCONTRO NACIONAL DE CONFORTO NO AMBIENTE CONSTRUÍDO, 4, 1997, Salvador. Anais... Salvador: FAUFBA/ LACAM; ANTAC, 1997, p. 49-58.

MACEIÓ. Lei Municipal n 5528 de dezembro de 2005. Institui o Plano Diretor de Maceió, estabelece diretrizes gerais de política de desenvolvimento urbano e dá outras providências. Disponível em:

$<$ http://www.maceio.al.gov.br>. Acesso em: 12 mar. 2014

. Lei Municipal n 5.593, de 8 de fevereiro de 2007. Institui o Código de Urbanismo e Edificações do Município de Maceió. Disponível em: <http://www.maceio.al.gov.br>. Acesso em: abr. 2013.

MELO, Juliana Duarte de. Caracterização climática da cidade de Maceió como subsídio a decisões de planejamento. 2009. 152 f. Dissertação (Mestrado em Arquitetura e Urbanismo) - Faculdade de Arquitetura e Urbanismo da Universidade Federal de Alagoas, Maceió, 2009.

SILVA, Geovany Jessé Alexandre da; ROMERO, Marta Adriana Bustos. O urbanismo sustentável no Brasil. A revisão de conceitos urbanos para o século XXI (Parte 02). Arquitextos, São Paulo: Vitruvius, ano 11, n. 129,8 fev. 2011. Disponível em: <http://vitruvius.es/revistas/read/arquitextos/11.129/3499>. Acesso em: 15 ago. 2012.

TORRES, Simone Carnaúba; FREITAS, Ruskin; BARBIRATO, Gianna Melo. Adensamento construtivo e qualidade climática urbana: análises de tipologias espaciais urbanas em clima quente e seco do Nordeste brasileiro. In: CONGRESSO LUSO BRASILEIRO PARA O PLANEJAMENTO URBANO, REGIONAL, INTEGRADO E SUSTENTÁVEL, 6, 2014, Lisboa. Anais PLURIS 2014. Lisboa: Fundação Calouste Gulbenkian, 2014, p. 1450-1461. 
Gianna Melo Barbirato, Simone Carnaúba Torres e

Ricardo Victor Rodrigues Barbosa

\section{AGRADECIMENTO}

Ao Conselho Nacional de Desenvolvimento Científico e Tecnológico (CNPq), pela bolsa de doutorado concedida para a autora Simone C. Torres, aluna do Programa de Pós-Graduação em Desenvolvimento Urbano da Universidade Federal de Pernambuco (UFPE).

Nota do editor

Submissão: jun. 2015

Aprovação: out. 2015

Paisagem e Ambiente: ensalos - N. 36 - São Paulo - P. 49 - 68 - 2015 